Review began 10/24/2021 Review ended 10/31/2021 Published 11/05/2021

\section{(c) Copyright 2021}

Sharif et al. This is an open access article distributed under the terms of the Creative Commons Attribution License CC-BY 4.0. which permits unrestricted use, distribution, and reproduction in any medium, provided the original author and source are credited.

\title{
Association Between Keratoconus and Shoulder Dislocation: A Cross-Sectional Study
}

Walid Sharif ${ }^{1}$, Khaled A. Elubous ${ }^{1}$, Zuhair Sharif ${ }^{1}$, Saif Aldeen AlRyalat ${ }^{1}$, Hashem E. Al Hawamdeh ${ }^{2}$, Mohammed A. Abu-Rumaileh ${ }^{3}$, Aws Khanfar ${ }^{2}$, Muawyah D. Al Bdour ${ }^{1}$, Osama H. Ababneh ${ }^{1}$

1. Department of Ophthalmology, Jordan University Hospital/The University of Jordan, Amman, JOR 2. Department of Orthopaedics, Jordan University Hospital/The University of Jordan, Amman, JOR 3. Department of Endocrinology, The University of Jordan, School of Medicine, Amman, JOR

Corresponding author: Walid Sharif, walid.sharif@nhs.net

\section{Abstract \\ Introduction}

Few studies have highlighted the correlation between shoulder dislocation and keratoconus (KC). This study aimed to examine the association between $\mathrm{KC}$ and shoulder dislocation using patients with $\mathrm{KC}$ and matched controls.

\section{Methods}

This cross-sectional study was conducted at Jordan University Hospital. We included patients diagnosed with KC from Jordan University Hospital's Ophthalmology Department between 2015 and 2018. We also included age- and sex-matched controls recruited randomly from fitness centers and shopping malls. All participants had complete ophthalmic and orthopedic assessments. KC was diagnosed by clinical examination followed by Pentacam (Scheimpflug Images, Oculyzer, WaveLight, Alcon, USA) confirmation.

\section{Results}

A total of 238 patients, with a mean age of $29.53( \pm 11.20)$ years, were included in this study. They were 144 (60.5\%) men and 94 (39.5\%) women. Moreover, 120 (50.4\%) had KC while 118 (49.6\%) did not have KC. Only 11 (4.6\%) patients had previous shoulder dislocation. We did not find a significant difference in the frequency of shoulder dislocation between patients with and without $\mathrm{KC}(\mathrm{p}=0.512)$.

\section{Conclusion}

This study provides further evidence on the lack of association between shoulder dislocation and KC, an association that was presumed due to shared collagen characteristics.

Categories: Ophthalmology, Orthopedics, Other

Keywords: shoulder dysfunction, recurrent dislocation shoulder, joint hyperlaxity, shoulder dislocation, keratoconus

\section{Introduction}

Keratoconus (KC) is the most prevalent form of corneal ectasia characterized by non-inflammatory progressive central or paracentral steepening and thinning leading to myopia, irregular astigmatism, and corneal scarring [1-2]. Commonly reported histopathological findings are scarring of Bowman's layer and anterior stroma with collagen fragmentation, fibrillation, and fibroblastic activity. Interestingly, yet underreported, studies have investigated the association between KC and joint hypermobility [3-6]. Examples of hypermobility conditions that may result in shoulder joint laxity and, thus, potentially increased risk of KC, include primary joint hypermobility syndrome [7], Ehlers-Danlos syndrome [8], and Marfan syndrome [9]. Patients with systemic hypermobility collagen disorders can also present with frequent joint dislocations and subluxations, chronic musculoskeletal pain, soft skin that may be elastic, osteoporosis, early-onset osteoarthritis, and cardiovascular abnormalities such as mitral valve prolapse [7].

Due to limited literature on this topic, this study aimed to examine the association between KC and shoulder dislocation using patients with KC and matched controls.

\section{Materials And Methods}

This study was conducted at Jordan University Hospital to assess the association between KC and shoulder dislocation. All participants provided verbal informed consent. The study adhered to the principles of the Declaration of Helsinki, and the institution's research development committee granted ethical approval.

\section{Patient selection}




\section{Cureus}

We included cases diagnosed with KC from Jordan University Hospital Ophthalmology Department between 2015 and 2018. We also included age- and sex-matched controls recruited randomly from fitness centers and shopping malls. They were screened and did not have any ophthalmic comorbidities including KC. All participants had complete ophthalmic examinations and investigations. KC was diagnosed by clinical examination, followed by Pentacam confirmation (Scheimpflug Images, Oculyzer, WaveLight, Alcon, USA).

All participants were prospectively assessed by the hospital's orthopedic department for shoulder instability using the Beighton score to quantify joint laxity and hypermobility. Patients that scored five of nine were considered to have positive joint hyperlaxity. Patients with non-traumatic shoulder dislocations were included in the study. The exclusion criteria were other ophthalmic and orthopedic comorbidities and traumatic causes of shoulder dislocation. To further reduce bias, all participants' shoulder assessments were conducted blindly by orthopedic clinicians.

\section{Main outcomes measures and follow-up}

The main outcome measures were shoulder dislocation, spectacle dependence, contact lens use, crosslinking, penetrating keratoplasty, intrastromal corneal rings, first-degree relative, second-degree relative, third-degree relative, consanguinity, eye rubbing, dryness, smoking, vernal keratoconjunctivitis (VKC), asthma, eczema, hypertension, and diabetes mellitus. Since it is a cross-sectional study, these measures were recorded at the last follow-up visit.

\section{Statistical analysis}

We used SPSS version 21.0 (IBM Corp., Armonk, NY) in our analysis. We used mean ( ${ }^{ \pm}$standard deviation) to describe continuous variables (e.g., age). We used count (frequency) to describe other nominal variables (e.g., sex). We performed the Mann-Whitney U test to analyze the median age difference between patients with shoulder dislocation and those without and used the independent sample t-test to analyze the mean age of patients with KC and controls. We also performed the chi-square test to analyze the difference in frequency between patients with and without KC in regard to shoulder dislocation. In addition, we used the chi-square test to analyze the difference between patients with and without $\mathrm{KC}$ and between patients with a shoulder dislocation and those without in regard to other nominal variables. We adopted a p-value of 0.01 as a significant threshold to account for multiple variable analysis.

\section{Results}

A total of 238 patients, with a mean age of $29.53( \pm 11.20)$ years, were included in this study. There were 144 (60.5\%) men and 94 (39.5\%) women. Moreover, 120 (50.4\%) had KC while 118 (49.6\%) did not have KC. Only 11 (4.6\%) patients had previous shoulder dislocation. We did not find a significant difference in the frequency of shoulder dislocation between patients with and without KC and $(p=0.512)$, as shown in Figure 1. No participants had systemic collagen-related disorders.

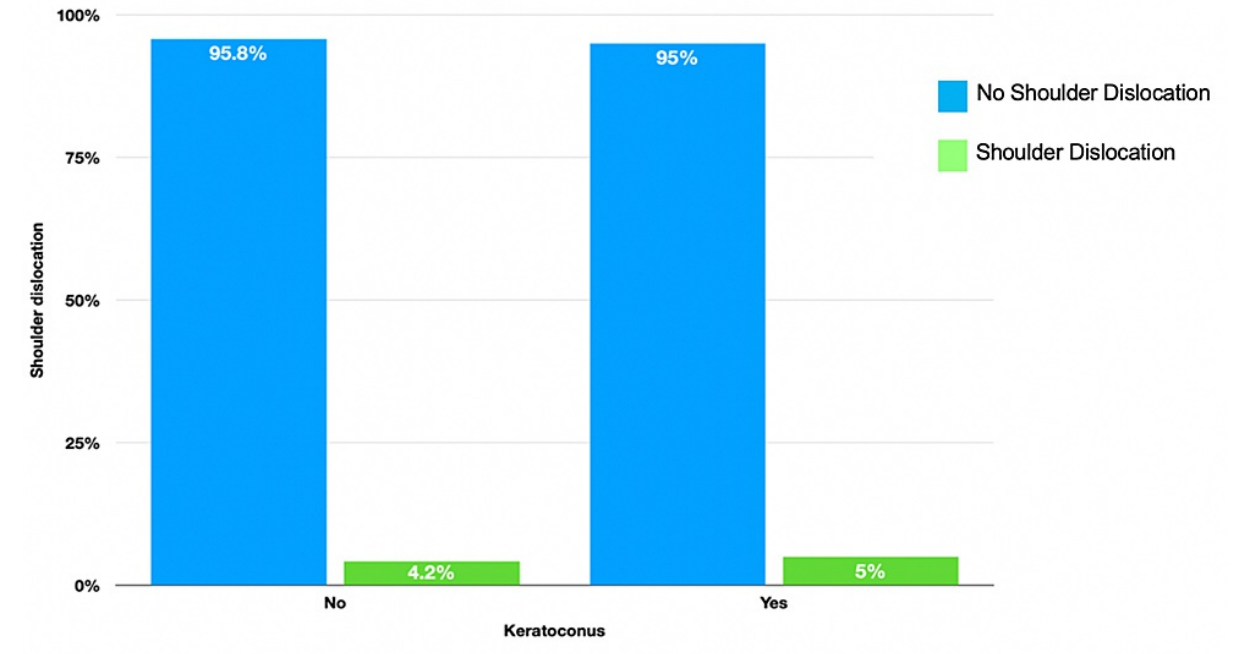
FIGURE 1: Comparison in the percentage of shoulder dislocation
between patients with keratoconus and their matched controls

In regard to KC, we found a significant age difference $(\mathrm{p}<0.001)$, with the mean age for patients with KC as $31.60( \pm 13.39)$ years compared to $27.43( \pm 7.92)$ years for patients without KC. Table 1 presents the 


\section{Cureus}

characteristics of patients with and without KC.

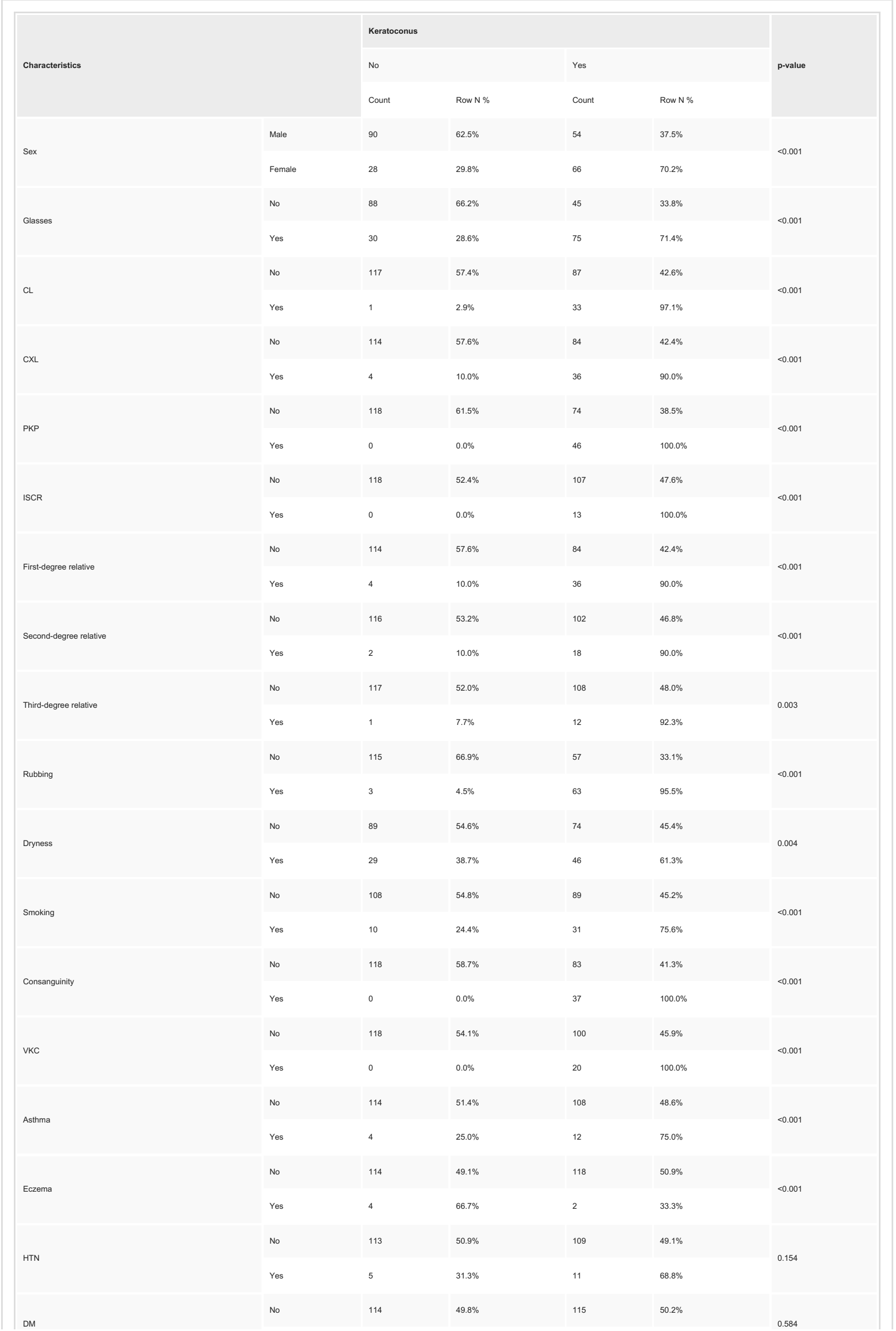




\section{Cureus}

\section{TABLE 1: Characteristics of patients with and without keratoconus}

Abbreviations: $\mathrm{CL}$, contact lens wear; CXL, crosslinking; PKP, penetrating keratoplasty; ISCR, intrastromal corneal ring; VKC, vernal keratoconjunctivitis; HTN, hypertension; DM, diabetes mellitus

In the analysis of the differences between patients with and without KC, we found a significant difference in regard to eye rubbing $(\mathrm{p}<0.001)$, where $63(95.5 \%)$ of patients with KC excessively rub their eyes, compared to only three (4.5\%) in patients without KC. We also found that VKC did not occur in patients without KC. In addition, we found that having first-degree relatives with KC is common among patients with KC (36 [90\%] compared to four patients without KC $[10 \%])$, which showed a statistically significant difference $(\mathrm{p}<0.001)$. A similar correlation was noted among second and third-degree relatives. Regarding consanguinity, we found that 37 (100\%) of patients with KC had a consanguinity factor compared to zero patients without KC $(\mathrm{p}<0.001)$.

Asthma had a higher prevalence in patients with KC (12 [75\%]) compared to those in patients without KC (4 [25\%]), which showed a statistically significant difference $(\mathrm{p}<0.001)$. Moreover, eczema was found in two (33.3\%) patients with KC compared to four (66.7\%) patients without KC, which showed a statistically significant difference $(\mathrm{p}<0.001)$.

Our study also found that $75 \%$ of patients with KC had asthma $(\mathrm{p}<0.001)$. There were no statistically significant differences for diabetes and hypertension among patients with and without $\mathrm{KC}(\mathrm{p}=0.584$ and $\mathrm{p}=$ 0.154 , respectively).

We did not find a significant difference in median age between patients with a shoulder dislocation and those without $(p=0.329)$. On the chi-square test, we did not find a significant sex difference between patients with shoulder dislocation $(\mathrm{p}=0.231$ ). Table 2 shows the characteristics of patients with and without a history of shoulder dislocation and the results of the difference analysis. In the analysis of the differences between patients with a shoulder dislocation and those without, we found a significant difference in regard to wearing glasses $(\mathrm{p}=0.001)$, where $10(90.9 \%)$ patients with shoulder dislocation are wearing glasses as compared to 95 (41.9\%) patients without shoulder dislocation. We also found that having first-degree relatives with $\mathrm{KC}$ is significantly more common in patients with shoulder dislocation $(\mathrm{p}=0.004)$, with six (54.5\%) patients who had shoulder dislocation compared to 34 (15\%) of patients who did not have shoulder dislocation. Moreover, eczema was found in $27.3 \%$ of patients who had shoulder dislocation compared to $1.3 \%$ of patients who did not have shoulder dislocation, showing a statistically significant difference $(\mathrm{p}=$ $0.001)$.

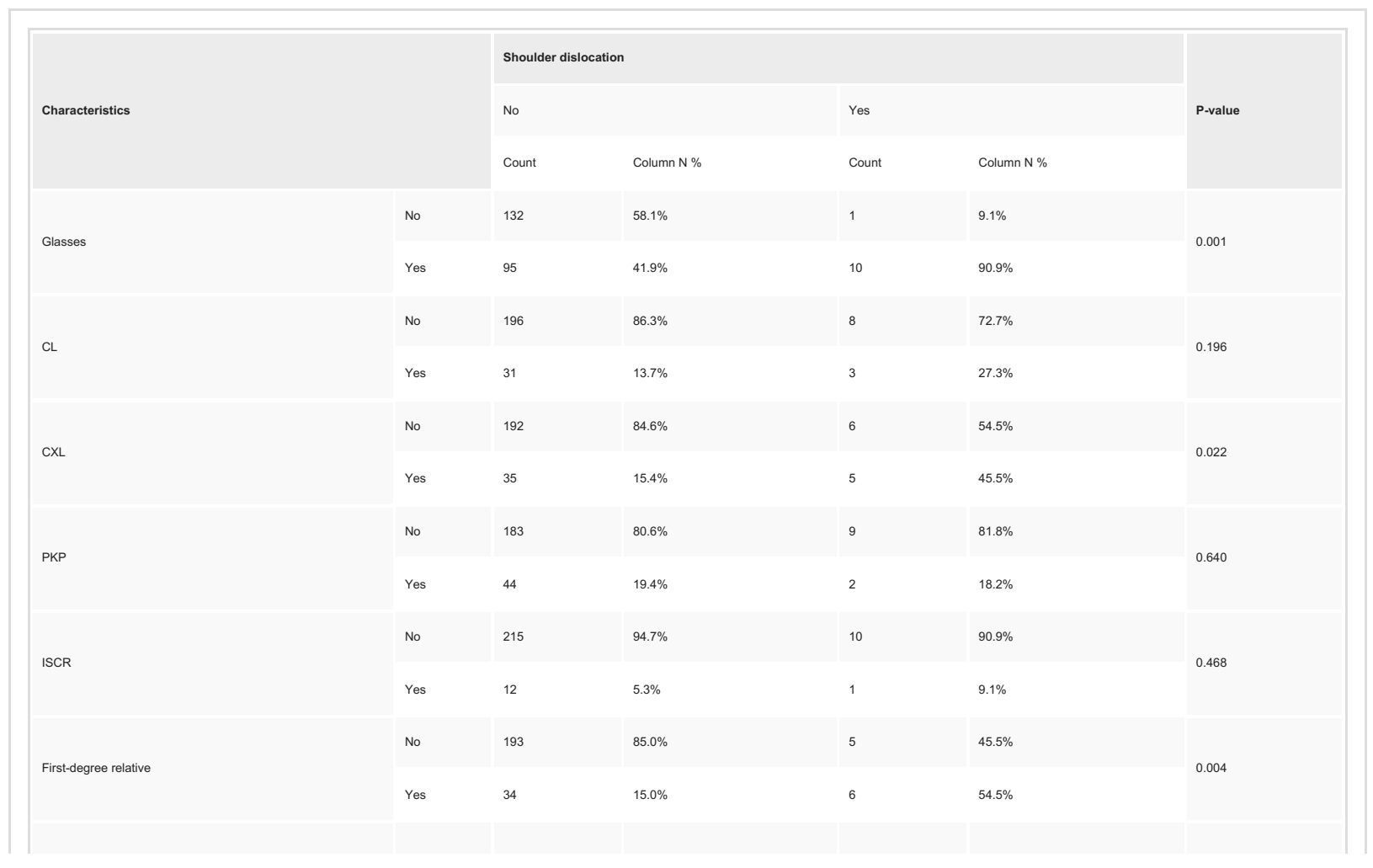




\section{Cureus}

\begin{tabular}{|c|c|c|c|c|c|c|}
\hline \multirow[t]{2}{*}{ Second-degree relative } & No & 210 & $92.5 \%$ & 8 & $72.7 \%$ & \multirow[t]{2}{*}{0.054} \\
\hline & Yes & 17 & $7.5 \%$ & 3 & $27.3 \%$ & \\
\hline \multirow{2}{*}{ Third-degree relative } & № & 215 & $94.7 \%$ & 10 & $90.9 \%$ & \multirow{2}{*}{0.468} \\
\hline & Yes & 12 & $5.3 \%$ & 1 & $9.1 \%$ & \\
\hline \multirow{2}{*}{ Rubbing } & № & 166 & $73.1 \%$ & 6 & $54.5 \%$ & \multirow{2}{*}{0.158} \\
\hline & Yes & 61 & $26.9 \%$ & 5 & $45.5 \%$ & \\
\hline \multirow{2}{*}{ Dryness } & No & 158 & $69.6 \%$ & 5 & $45.5 \%$ & \multirow{2}{*}{0.091} \\
\hline & Yes & 69 & $30.4 \%$ & 6 & $54.5 \%$ & \\
\hline \multirow{2}{*}{ Smoking } & No & 191 & $84.1 \%$ & 6 & $54.5 \%$ & \multirow{2}{*}{0.025} \\
\hline & Yes & 36 & $15.9 \%$ & 5 & $45.5 \%$ & \\
\hline \multirow{2}{*}{ Consanguinity } & № & 192 & $84.6 \%$ & 9 & $81.8 \%$ & \multirow{2}{*}{0.533} \\
\hline & Yes & 35 & $15.4 \%$ & 2 & $18.2 \%$ & \\
\hline \multirow{2}{*}{ VKC } & No & 207 & $91.2 \%$ & 11 & $100.0 \%$ & \multirow{2}{*}{0.373} \\
\hline & Yes & 20 & $8.8 \%$ & 0 & $0.0 \%$ & \\
\hline \multirow{2}{*}{ Asthma } & No & 214 & $94.3 \%$ & 8 & $72.7 \%$ & \multirow{2}{*}{0.030} \\
\hline & Yes & 13 & $5.7 \%$ & 3 & $27.3 \%$ & \\
\hline \multirow{2}{*}{ Eczema } & No & 224 & $98.7 \%$ & 8 & $72.7 \%$ & \multirow{2}{*}{0.001} \\
\hline & Yes & 3 & $1.3 \%$ & 3 & $27.3 \%$ & \\
\hline \multirow{2}{*}{ HTN } & No & 213 & $93.8 \%$ & 9 & $81.8 \%$ & \multirow{2}{*}{0.163} \\
\hline & Yes & 14 & $6.2 \%$ & 2 & $18.2 \%$ & \\
\hline \multirow{2}{*}{ DM } & No & 219 & $96.5 \%$ & 10 & $90.9 \%$ & \multirow{2}{*}{0.352} \\
\hline & Yes & 8 & $3.5 \%$ & 1 & $9.1 \%$ & \\
\hline
\end{tabular}

\section{TABLE 2: Patient characteristics with and without a history of shoulder dislocation}

Abbreviations: $\mathrm{CL}$, contact lens wear; CXL, crosslinking; PKP, penetrating keratoplasty; ISCR, intrastromal corneal ring; VKC, vernal keratoconjunctivitis; HTN, hypertension; DM, diabetes mellitus

\section{Discussion}

$\mathrm{KC}$ is still regarded as a nonspecific sign representing a generalized collagen systemic disorder [6]. The oldest study in literature concluded that $50 \%$ of patients with KC had hypermobile joints [3]. Another study highlighted that $67 \%$ of patients with KC had associated connective tissue symptoms and abnormalities [4]. Morris and Woodward have concluded that subjects with KC are five folds more likely to have hypermobility of the metacarpophalangeal and wrist joints but less likely to have increased mobility of the trunk and knees [5].

However, other studies have highlighted the lack of association between KC and joint hypermobility. One study could not find a statistically significant difference in the prevalence of hypermobile joints and KC [6]. Marfan syndrome and other collagen disorders have a similar collagenous impact on ocular tissues [10], and shoulder laxity is also another common manifestation of such diagnoses. This explains why some studies found associations between this joint presentation and KC [10-11]. However, this association is not conclusive and dependent on the underlying cause for shoulder laxity. Our study did not find a statistically significant difference in the frequency of shoulder dislocation between patients with and without $\mathrm{KC}(\mathrm{p}=$ $0.512)$.

Shoulder laxity is ultimately a nonspecific sign, where the underlying etiology can be the result of a range of other conditions or factors, entirely unconnected to a systemic collagen condition that would also present a risk factor for developing KC [12]. For instance, shoulder laxity can also be the result of previous traumas and therefore are entirely unrelated to the development of KC. Essentially, as should be foremost when examining any data regarding associations, associations do not denote causation. Instead, shoulder laxity 
may be related to a higher risk of developing KC but does not directly cause the ocular condition. Consequently, unless an individual also presents with other signs and symptoms of a systemic collagenous pathology that affects joint stability, KC is not directly related to shoulder laxity. Moreover, this association is only manifested when the underlying cause of the hypermobility is indeed the result of a systemic, hypermobility condition [10].

Many studies have reported different strengths of association between KC and systemic, familial, and ocular factors. Positive family history has been reported in 6-8\% of cases, and its prevalence in first-degree relatives is 15-67 times higher than in the general population [13]. Our study found that first-degree relatives with $\mathrm{KC}$ are common among patients with KC (36 [90\%]) compared to patients without KC (4 [10\%]), which showed a statistically significant difference $(\mathrm{p}<0.001)$. A similar correlation was noted among second and third-degree relatives. Interestingly, we found that having first-degree relatives with $\mathrm{KC}$ is significantly more common in patients with shoulder dislocation $(\mathrm{p}=0.004)$, with six $(54.5 \%)$ patients who had shoulder dislocation compared to 34 (15\%) for patients who did not have shoulder dislocation.

Several studies examined the association between eye rubbing and the development of KC [14-18]. Our study has shown that 63 (95.5\%) patients with KC excessively rub their eyes compared to only three (4.5\%) patients without KC, which showed a statistically significant difference. This association may be due to the activation of wound healing processes and signaling pathways secondary to mechanical epithelial trauma and direct rubbing-related mechanical trauma to keratocytes and increased hydrostatic pressure in the eye [19].

We believe this study has limitations that need to be considered in future projects. Larger sample size studies are needed to further validate our findings. The retrospective nature also indicated reliance on nonstudy observers for $\mathrm{KC}$ data recording. We were unable to validate some participants' recall of family history information as family members were unreachable. Shoulder dislocation also depends on the activities of a person; someone with a high Beighton score but a sedentary lifestyle might not have shoulder dislocation. Therefore, shoulder dislocations may have to be compared in the background of similar lifestyles in future studies.

\section{Conclusions}

Our study highlights the lack of association between KC and shoulder laxity and thus will further add to the limited literature on this interesting topic. Unless an individual also presents with other signs and symptoms of a systemic hypermobility collagen-related disorder, KC is not directly associated with shoulder laxity.

\section{Additional Information \\ Disclosures}

Human subjects: Consent was obtained or waived by all participants in this study. Research development committee of Jordan University Hospital issued approval NA. Animal subjects: All authors have confirmed that this study did not involve animal subjects or tissue. Conflicts of interest: In compliance with the ICMJE uniform disclosure form, all authors declare the following: Payment/services info: All authors have declared that no financial support was received from any organization for the submitted work. Financial relationships: All authors have declared that they have no financial relationships at present or within the previous three years with any organizations that might have an interest in the submitted work. Other relationships: All authors have declared that there are no other relationships or activities that could appear to have influenced the submitted work.

\section{References}

1. Gordon-Shaag A, Millodot M, Shneor E, Liu Y: The genetic and environmental factors for keratoconus . Biomed Res Int. 2015, 2015:795738. 10.1155/2015/795738

2. Espandar L, Meyer J: Keratoconus: overview and update on treatment . Middle East Afr J Ophthalmol. 2010, $17: 15-20$.

3. Robertson I: Keratoconus and the Ehlers-Danlos syndrome: a new aspect of keratoconus . Med J Aust. 1975, 1:571-3. 10.5694/j.1326-5377.1975.tb111590.x

4. Ihalainen A: Clinical and epidemiological features of keratoconus genetic and external factors in the pathogenesis of the disease. Acta Ophthalmol Suppl. 1986, 178:1-64.

5. Woodward EG, Morris MT: Joint hypermobility in keratoconus. Ophthalmic Physiol Opt. 1990, 10:360-2. 10.1111/j.1475-1313.1990.tb00882.x

6. Street DA, Vinokur ET, Waring GO 3rd, Pollak SJ, Clements SD, Perkins JV: Lack of association between keratoconus, mitral valve prolapse, and joint hypermobility. Ophthalmology. 1991, 98:170-6. 10.1016/s0161-6420(91)32320-0

7. Skoumal M, Haberhauer G, Mayr H: Concomitant diseases in primary joint hypermobility syndrome [Article in German]. Med Klin (Munich). 2004, 99:585-90. 10.1007/s00063-004-1086-6

8. Walkden A, Burkitt Wright E, Au L: Brittle cornea syndrome: current perspectives. Clin Ophthalmol. 2019, 13:1511-6. 10.2147/OPTH.S185287

9. Gehle P, Goergen B, Pilger D, Ruokonen P, Robinson PN, Salchow DJ: Biometric and structural ocular manifestations of Marfan syndrome. PLoS One. 2017, 12:e0183370. 10.1371/journal.pone.0183370 


\section{Cureus}

10. Beene LC, Traboulsi EI, Seven I, Ford MR, Sinha Roy A, Butler RS, Dupps WJ Jr: Corneal deformation response and ocular geometry: a noninvasive diagnostic strategy in Marfan syndrome. Am J Ophthalmol. 2016, 161:56-64.e1. 10.1016/j.ajo.2015.09.027

11. Robati RM, Einollahi B, Einollahi H, Younespour S, Fadaifard S: Skin biophysical characteristics in patients with keratoconus: a controlled study. Scientifica (Cairo). 2016, 2016:6789081. 10.1155/2016/6789081

12. Dumont GD, Russell RD, Robertson WJ: Anterior shoulder instability: a review of pathoanatomy, diagnosis and treatment. Curr Rev Musculoskelet Med. 2011, 4:200-7. 10.1007/s12178-011-9092-9

13. Wang Y, Rabinowitz YS, Rotter JI, Yang H: Genetic epidemiological study of keratoconus: evidence for major gene determination. Am J Med Genet. 2000, 93:403-9.

14. Rabinowitz YS: Keratoconus. Surv Ophthalmol. 1998, 42:297-319. 10.1016/s0039-6257(97)00119-7

15. McMonnies CW: Abnormal rubbing and keratectasia. Eye Contact Lens. 2007, 33:265-71. 10.1097/ICL.0b013e31814fb64b

16. Bawazeer AM, Hodge WG, Lorimer B: Atopy and keratoconus: a multivariate analysis . Br J Ophthalmol. 2000, 84:834-6. 10.1136/bjo.84.8.834

17. Zadnik K, Barr JT, Edrington TB, et al.: Baseline findings in the Collaborative Longitudinal Evaluation of Keratoconus (CLEK) Study. Invest Ophthalmol Vis Sci. 1998, 39:2537-46.

18. Weed KH, MacEwen CJ, Giles T, Low J, McGhee CN: The Dundee University Scottish Keratoconus study: demographics, corneal signs, associated diseases, and eye rubbing. Eye (Lond). 2008, 22:534-41. 10.1038/sj.eye.6702692

19. McMonnies CW: Mechanisms of rubbing-related corneal trauma in keratoconus . Cornea. 2009, 28:607-15. 10.1097/ICO.0b013e318198384f 